\title{
КВАЗИДУХОВНОСТЬ КАК ПРЕВРАЩЕННАЯ ФОРМА ДУХОВНОСТИ
}

\section{В.С. Писчиков, М.М. Холин}

Европейская философия в лице своих наиболее глубоких и проницательных мыслителей уже в XIX столетии осознала начало духовного кризиса западной цивилизации. Одними из первых среди них были Сёрен Кьеркегор и Карл Маркс. К. Маркс непосредственно связал этот кризис с феноменом тотального отчуждения, характерного для буржуазного общества. Философы ХХ века констатировали развитие и углубление кризиса духовности, пытаясь выявить его причины, формы проявления и особенности, осмыслить характер воздействия на бытие человека. С различных мировоззренческих и методологических позиций, с разной степенью основательности и глубины это делали Н. Бердяев, О.Шпенглер, Э. Гуссерль, Э.Фромм, экзистенциалисты, представители Франкфуртской школы и другие.

В настоящее время идея кризиса духовности техногенной цивилизации получила в философии и социологии фактически статус общепризнанной. В российской и украинской философской мысли она приобрела особую актуальность и резонанс в последнее пятнадцатилетие в связи с радикальными социальными изменениями и связанной с этим процессом коренной трансформацией духовных ценностей.

В обширной философской и научно-гуманитарной литературе на данную тему внимание авторов сосредоточено, главным образом, на понятии духовности как антропокультурном феномене, ее атрибутах и функциях, национальных особенностях. Что касается кризисных форм проявления духовности, то они становятся предметом специального рассмотрения гораздо реже, а когда это и происходит, то исследование их, на наш взгляд, носит чаще односторонний характер, ограничиваясь

Актуальні проблеми духовності

(Відп. ред.: Я.В. Шрамко)

Кривий Ріг (2006), 12-22 
описанием и констатацией негативности этих форм как бездуховности, псевдодуховности и антидуховности.

Возможность более глубокого осмысления современного кризиса духовности, по нашему мнению, открывает применение понятия превращенной формы, которое было введено и плодотворно использовалось К. Марксом в «Капитале» и прежде всего в подготовительных материалах к нему (См. [6, с.7]). Оно характеризует «строение и способ функционирования сложных систем» и позволяет «исследовать видимые зависимости и эффекты, выступающие на поверхности целого в качестве того, что Маркс называл „формой его действительности, или, точнее, формой ... действительного существования“» $[8$, с. 386].

Категория «превращенная форма» имплицитно содержит в себе: а) идею о возможности искажения, извращения при определенных условиях содержания социальных явлений; б) признание того, что такое искажение вызвано объективными деформациями в функционировании социальной системы; в) понимание превращенной формы как «восполняющей и замещающей» [8, с.387], которая берет на себя все основные функции того явления, которое она восполняет и замещает. Последнее означает, что превращенную форму определенного социального явления, например, духовности следует рассматривать не просто как аномалию, которая порождена исключительно субъективными факторами человеческой деятельности, а как явление, необходимое для сушествования социума, пока в нем сохраняются вызвавшие эту форму объективные деформации.

Как нам представляется, имеются вполне достаточные основания рассматривать утверждающуюся в современном обществе духовность как превращенную форму - квазидуховность, которая выступает в качестве суррогата, имитации подлинной духовности. Замещая духовность, квазидуховность воспроизводит внешние формы ее бытия, а также выполняет ее основные социокультурные функции - смыслообразующую и человекотворческую. Однако осуществляется это на основе иных по своему содержанию фундаментальных ценностей. Прежде, чем ответить на вопрос, что представляют собой эти ценности и как они организованы, попытаемся выявить социальные факторы, обусловившие их.

1. В качестве основного, на наш взгляд, следует назвать отчуждение. Зафиксированный, как уже упоминалось, еще К. Марксом в середине XIX столетия феномен отчуждения, как и предвидел гениальный мыслитель, не стал достоянием истории. Более того, пронизывая все сферы жизни современного общества, отчуждение продолжает углу- 
бляться и прогрессировать. Речь идет, прежде всего, хотя и не только, о социально-экономическом и антропологическом отчуждении.

Все большее усложнение процессов в современной рыночной экономике при одновременном возрастании их автономности привело к тому, что отдельный индивид фактически лишился объективных механизмов воздействия на экономические условия своего существования. Несмотря на развитость в современном западном обществе политической демократии, она в преобладающей степени имеет формальный, юридический характер и поэтому также оставляет индивиду слишком мало возможностей для регулирования социально-политических условий своей жизни. Развертывающаяся же в современном мире глобализация еще больше усиливает неподвластность индивиду социальных процессов: «Силы, формирующие условия, в которых нам приходится противостоять тем или иным проблемам, находятся за пределами досягаемости любых институтов, изобретенньх демократией за два столетия истории»,- констатирует известный современный британский социолог З. Бауман [3, с. 188].

Интегральным следствием процессов отчуждения в экономической, социально-политической и других сферах жизни современного западного общества является положение, когда «удержание в своих руках настоящего, уверенность в том, что ты контролируешь собственную судьбу, как раз и представляют собой то, чего люди в нашем типе общества самым очевидным образом лишены» [3, с. 188]. Ситуация зыбкости, неустойчивости положения индивида в обществе, неконтролируемости жизненных обстоятельств его существования, обусловленная феноменом отчуждения, дополняется и усугубляется небывалым динамизмом современной жизни во всех ее проявлениях - в сфере трудовой деятельности, в культурной среде, в информационном пространстве и др. Как правило, эти изменения по отношению к индивиду осуществляются случайно и стихийно, а поэтому не поддаются прогнозированию с его стороны. 3. Бауман: «Сегодня условия изменяются внезапно, попирая любые разумные представления и не следуя твердой логике или внятным схемам» $[3, \mathrm{c} . \mathrm{LV}]$.

Все это вместе взятое объективно порождает у индивида ощущение временности, непрочности настоящего и проблематичности будущего, формирует психологию жить сегодняшним днем, ставить перед собой кратковременные цели, не заглядывая далеко вперед и не стремясь к стратегическим целям. Тем самым объективными условиями жизни подрывается доверие к вечным и абсолютным духовным ценностям, они все чаще оказываются невостребованными. 
Отчуждение на уровне жизненных условий существования индивида в современном обществе обусловливает антропологическое отчуждение - отчуждение фундаментальных качеств его природы как человека. Суть последнего заключается в том, что индивиду становятся все более чуждыми или безразличными многие его истинно человеческие, социальные качества и потребности, а их место занимают биологические, прежде всего телесные, в удовлетворении которых индивид и чувствует себя человеком.

Возвышение роли природного в жизни человека в ущерб социальному, прежде всего моральному началу, не могло не повлечь за собой качественной трансформации в системе жизненных ценностей личности. На первый план в этой системе все больше выдвигаются и гипертрофируются запросы и проявления телесной жизни человека.

2. Важнейшую особенность образа жизни современного человека в обществе массового потребления выражает определение его как потребительского. Объективной социальной основой этого образа жизни являются интересы капитала в производстве, а следовательно, реализации и потреблении всё возрастающей и непрерывно обновляющейся массы вещей и услуг. В результате раскручивается, приобретая ускорение, маховик потребительства, в орбиту которого все больше втягивается и сфера духовного производства - сфера массовой культуры. Поэтому сегодня «для всего мира актуальна проблема разрастания ... потребительского отношения ко всему» $[9$, с.6].

Кредо потребительства как психологической установки и жизненной ориентации - не созидать, творить, а потреблять готовое. Этим прежде всего и обусловливается отмечаемый многими учеными и практиками разных стран, возникший и все нарастающий дефицит творческих личностей во всех сферах жизни современного общества: «Мой клинический опыт в области психологии, - отмечает, например, в связи с этим известный современный итальянский философ, социолог и психолог А. Менегетти,- подтверждает: во всем мире ощущается недостаток в человеке творческом, обладающем высочайшим интеллектом» $[9$, с.6]. Потребляемые вещи, материальные ценности и услуги, их количество, стоимость и престижность - вот зеркало, в которое смотрится индивид-потребитель, желая увидеть, как ему кажется, свое подлинное лицо, определить свои истинное достоинство и значимость.

Вещизм как жизненная ориентация вносит радикальные изменения в мировоззрение индивида: складывается заземленное, ограниченное узкими рамками обыденных интересов, гедонистическое восприятие жизни, человеческих взаимоотношений. Такое мировосприятие транс- 
формирует и мир жизненных ценностей индивида, в котором доминирующими становятся материальные, утилитарно-житейские ценности. Духовные же ценности, тем более высшие и абсолютные, либо за ненадобностью исключаются, либо отодвигаются на периферию системы ценностных ориентаций личности, неизбежно изменяясь при этом.

3. Трудно найти сейчас среди философов и социологов тех, кто отрицал бы индивидуалистическую природу психологии и образа жизни западного человека, тот факт, что «индивидуализм ... лежит в основе современного мироощущения» [5, с. 109]. Расхождения существуют лишь в оценке характера воздействия индивидуализма на бытие человека и жизнь общества, а также степени и масштабов его развития.

Рассматривая индивидуализм в интересующем нас аспекте, а именно, в контексте развития духовности личности, мы будем исходить из его сущности. При всех расхождениях в позициях общепризнанным является, что индивидуализм сосредотачивает, фокусирует внимание, интересы и цели индивида прежде всего, всегда и во всем на себе самом, собственном «Я». Мировоззренческой основой индивидуализма является эгоцентризм, сужающий пространство человеческого бытия до масштабов и границ бытия индивида. Г. Батищев: «Для индивида-атома самостоятельность достижима только ценой самовыключения из сущностной сопричастности с другими, то есть самоизоляции и ценностного одиночества в качестве для себя самой идеальной онтологической единицы» [1, с. 114$]$.

Тем самым индивидуализм неизбежно ведет к сужению и обеднению мира жизненных ценностей индивида, доминированию прагматических мотивов в их выборе. Принимаемые ценности, включая и высшие духовные, индивидуалист считает вправе интерпретировать, исходя из своих интересов и представлений, так как с его позиции «последний смысл (ценностей) не гарантирован никем и ничем, не положен извне ... Не дарован в качестве вечного и абсолютного: „Вечные ценности?" О, сколько вашей душе посильно и угодно. . . В любом случае это личная позиция. Основанная на уникальном человеческом существе, на его индивидуальной суверенности» [2, с. 50]. Так излагает, как бы изнутри, суть индивидуалистической позиции Л. Баткин, видящий в индивидуализме позитивный смысл. Но эта позиция фактически (не декларативно) ставит под вопрос правомерность и необходимость существования высших духовных ценностей как абсолютных и общезначимых, если, конечно, не воспринимать их как пустые слова-оболочки, которые каждый индивид наполняет собственным содержанием, 
облагораживая свои действия.

Объективной основой индивидуализма является противоречие индивидуального и социального. Прогнозы, согласно которым это противоречие с развитием буржуазного общества, в частности, с его демократизацией и трансформацией государства в «социальное государство» будет все более смягчаться и наполняться социальным содержанием, - не оправдались. В настоящее время многие философы Запада с тревогой констатируют прямо противоположное: усиление дисгармонии, расширение пространства отчужденности между частным и общественным в жизни западного человека. З.Бауман: «личное“ и „общественное“ позиционируются в двух разных мирах, не связанных друг с другом. В каждом из этих миров действует своя логика, практически непонятная в другом мире» [3, с. LIII]. Естественно, что эти безразличие и отчужденность в интересах между личным (индивидуальным) и социальным воспроизводится и в соотношении индивидуально- и социально значимых ценностей.

4. Трансформация традиционного западного общества в индустриальное, а затем и постиндустриальное сопровождалась радикальными, многосторонними преобразованиями системы социальных, в том числе, и духовных ценностей. В условиях ослабления, а затем и разрушения традиций был подорван и безусловный авторитет высших духовных ценностей. Ассоциировавшиеся с этими традициями и обосновывавшиеся ими, ценности стали также восприниматься как нечто отжившее и несовременное, старомодное.

Важно подчеркнуть, что этот процесс ломки традиций охватил не только сферу обыденной жизни, но и культуру в целом - мораль, искусство, философию, науку, следствием чего явились существенные изменения в мировосприятии и стиле мышления европейского человека. «Отныне, - констатирует по поводу сказанного Г. Гадамер, - преемственность традиций европейского мышления утрачивает свою континуальность» $[4$, с. 2]. Но разрушение традиций имело также своим результатом расширение сферы свободы личности в целом, свободы самовыражения ее в частности. И в данном контексте высшие духовные ценности стали зачастую восприниматься индивидуалистически ориентированной личностью с негативным оттенком - как противоречащие свободе личности императивы, ограничивающие ее оковы.

5. Столетиями в европейском обществе высшие духовные ценности освящались авторитетом христианства. Начавшийся в Новое время процесс секуляризации подорвал монопольное право религии на истину и в настоящее время привел к ослаблению ее реального вли- 
яния на жизнь человека. Одним из следствий этого процесса стало падение и авторитета высших духовных ценностей, сомнение в их абсолютности и верности, а тем самым, и открывшаяся возможность их релятивизации и субъективизации.

Таковы, на наш взгляд, важнейшие из тех факторов, которые обусловили перерождение духовности в квазидуховность. Раскрывая их содержание, мы не могли не затрагивать и смысла происходящих при этом изменений в духовности, которые выступают одновременно и в качестве сущностных характеристик квазидуховности. Обобщая сказанное, отметим, что важнейшими из этих характеристик являются следующие:

\section{1. Релятивизачия и субгективизация духовных иенностей.}

Эта особенность присуща содержанию всей квазидуховности, но прежде всего таким основополагающим ценностям как любовь, добро, красота, истина. Названные традиционные общечеловеческие ценности, понимаемые как абсолютные и вечные, являются фундаментальными в содержании духовности. Без них не может существовать и квазидуховность, так как в этом случае она не имела бы ничего общего с духовностью, не воспринималась бы как духовность и не могла бы выполнять ее функции. Понимание же высших духовных ценностей всего лишь как относительных и субъективных неизбежно привело к неопределенности их содержания и многозначности смысла, размыванию их границ и к утрате твердых, объективных критериев. Безусловно, и в таком качестве они могут быть для субъекта высшими духовными жизненными ценностями, ориентирами. Однако лишенные общезначимости и статуса абсолютности они уже не могут выполнять аналогичную функцию по отношению к обществу, его культуре в целом. Но тем самым они постепенно теряют свою значимость и смысл для бытия отдельной личности.

Релятивизация и субъективизация содержания истины ведет не только к отказу от понятия абсолютной истины и поиска ее объективных критериев, но и ставит под вопрос правомерность и необходимость самого понятия истины, в частности в науке. Наиболее явно эта тенденция нашла свое выражение в философии науки - в концепции «методологического анархизма» П. Фейерабенда. Другим, хотя и опосредованным, но не менее важным следствием отмеченной деформации содержания истины является ослабление веры в возможности человеческого разума, его дискредитация. Но разум, рациональность - это не только эпистемологическая, но и общекультурная ценность. Являясь, 
по выражению Г. Гадамера, «всеобщей формой осуществления рефлексии» $[4$, с.634], рациональность тем самым выступает и в качестве способа бытия духовности на всех стадиях ее развития и во всех формах проявления.

Еще более радикальные изменения происходят в содержании добра и красоты как аксиологических категорий и духовных ценностей. Их релятивизация и субъективизация превращают грань между добром и злом, прекрасным и безобразным в весьма условную. Теряя свою определенность и ясные очертания, добро и красота уже не могут служить в качестве надежного заслона на пути злого и безобразного, которые все шире и агрессивнее входят в жизнь как индивида, так и социума, превращаясь в естественный, привычный элемент повседневности происходит так называемая «прозаизация» зла и безобразного.

Релятивизация категории красоты имеет еще одно весьма важное следствие: она ведет (и уже привела) к массовому падению уровня эстетических вкусов. Лишенный твердых критериев, индивид схватывает некоторые, как правило, лежащие на поверхности, бросающиеся в глаза признаки красивого, прежде всего, его оригинальность. Безусловно, это качество - важный и необходимый признак прекрасного, но далеко не единственный. Вне связи с другими его атрибутами, такими, как гармоничность, совершенство, естественность, высокая культура и мастерство, оригинальность приобретает характер самодостаточности и неизбежно абсолютизируется, гипертрофируется. Становясь самоцелью, самобытность мельчает и вырождается в оригинальничанье как ее внешнее подобие - броскость, вычурность, нечто шокирующее и эпатажное на грани (а порою и за нею) скандальности. Вполне естественно и логично, что такая «оригинальность» мирно уживается с антиподами красоты - безвкусицей, примитивизмом, вульгарностью в искусстве (массовая культура) и обыденной жизни, начиная от одежды и заканчивая языком и стилем поведения.

Девальвация любви как духовной и, прежде всего, нравственной ценности все более сужает пространство ее самоосуществления не только в сфере общественных, но и личностных отношений. В симбиозе с вещизмом и прагматизмом, присущими потребительскому образу жизни, релятивизированная любовь легко сдает свои позиции под натиском антигуманного и эгоистичного в жизни. Даже в сферу личностных взаимоотношений, включая родственные, дружеские и интимные, все больше проникают холодный расчет и прагматичность, и все чаще они воспринимаются здесь как уместные и естественные.

Выражением и отражением процесса релятивизации и субъективи- 
зации высших духовных ценностей является так называемая концепция «третьей правды», согласно которой все эти ценности лишаются статуса абсолютного критерия в оценке противоборства добра и зла, истины и лжи, любви и ненависти, прекрасного и безобразного. Такой критерий сторонники названной концепции предлагают искать с позиции «над» борьбой противоположных ценностей, некоей «третьей», нейтральной позиции.

\section{2. Изменение статуса высших духовных ценностей.}

Добро, любовь, красота, истина входят в содержание квазидуховности не только как относительные и субъективные ценности, но и постепенно лишаются своего статуса высших, вытесняясь на ее периферию либо, в лучшем случае, уравниваются с другими ценностями. Данная трансформация обусловлена уже отмечавшимися нами качественными изменениями в образе жизни современного человека, прежде всего, доминированием в нем потребительской, прагматической ориентации. В результате этого духовные интересы и соответствующие им ценности индивида оттесняются на второй план житейскими материальными ценностями, такими, как успех, карьера, престиж, связи, вещи и деньги.

Безусловно, ценности обыденной жизни всегда имели определенное значение для индивида, большее или меньшее в зависимости от уровня его духовного развития. Однако при этом, как правило, они рассматривались и самим индивидом, и обществом лишь в качестве житейских, утилитарных, не претендуя на статус смысложизненных ценностей. В современном же обществе идеологически облагораживаемые и популяризуемые через масс-медиа они возводятся в ранг высших жизненных ценностей, успешно конкурируя с традиционными и все более уверенно занимая их место в содержании превращенной формы духовности.

$\mathrm{K}$ аналогичному следствию, как уже нами отмечалось, ведет и гипертрофия запросов и проявлений биологической жизни индивида: на статус высших ценностей претендуют телесная красота, физическая сила, сексуальные достоинства и др. Чаще в этом процессе и его крайностях видят реакцию раскрепощенного человека XX столетия на подавление религией и культурой в целом в ходе предшествующей истории естественных биологических потребностей человека. Не отрицая определенного смысла в таком объяснении, мы полагаем, что главной причиной биологизации ценностей современного человека является сохраняющееся и прогрессирующее отчуждение его социальной сущности. 


\section{3. Трансформачия структуры духовности.}

Кроме изменений в содержании духовности, связанных с положением и статусом в ней высших духовных ценностей, необходимо отметить коренную трансформацию способа ее организации. Если духовность организована как иерархичный моноцентричный универсум, ядром которого являются смысложизненные ценности, то квазидуховность это гетерархически организованный полицентричный поливерсум. В ней состав ценностей и способ их организации, включая их иерархию, определяется субъектом и только им. Такой принцип организации исключает признание за какими бы то ни было ценностями статуса общезначимых и абсолютных: субъект и только он вправе по своему усмотрению наделить таким статусом любые ценности либо не наделять никаких. Постмодернистский лозунг «долой все иерархии и абсолюты!» как нельзя лучше выражает специфику структурной организации квазидуховности.

\section{4. Деформачия сущности духовности.}

Подлинной духовности в соответствии с ее природой присуща нравственно-гуманистическая интенция. Лежащие в ее основании высшие смысложизненные ценности выработаны обществом для формирования, сохранения и совершенствования в человеке человеческого начала в противоборстве со всем тем, что противостоит ему. Качественные изменения в содержании духовности в процессе ее трансформации в квазидуховность привели к утере ею своей нравственно-гуманистической сущности. Квазидуховность как псевдо-, а нередко и антидуховность выполняет антигуманную функцию в жизни общества и индивида, способствуя нарастанию в нем безнравственного и бесчеловечного.

Утверждение в обществе квазидуховности не означает, конечно, полного вытеснения из его жизни подлинной духовности: они как бы меняются местами и социальной ролью. На протяжении тысячелетий в центре культуры, как образец, идеал были высшие духовные ценности, псевдодуховность же, также всегда существовавшая, была на ее периферии и не претендовала в общественном мнении на статус подлинной духовности. В настоящее же время на периферию культуры все больше вытесняется духовность, становясь уделом меньшинства.

Однако при этом мы не имеем ввиду так называемую элитарную культуру и ее носителей, как это нередко утверждается. Элитарная культура в целом, за исключением отдельных ее образцов, на наш взгляд, также не может претендовать на статус сферы существования подлинной духовности. Ее отрыв от широкого социокультурного 
контекста, ориентация на избранных и посвященных обусловливают ее замкнутость и искусственную усложненность, интеллектуальный и профессиональный снобизм, возведенный в культ дух экспериментаторства, - все то, что также ведет к деформации подлинных духовных ценностей.

Перспективы духовности в ее противоборстве с квазидуховностью всецело связаны с преодолением обществом тех объективных деформаций в нем, которые вызвали и обусловливают существование квазидуховности - социокультурного и антропологического отчуждения, потребительства, индивидуализма и эгоизма.

\section{1 Литература}

[1] Батищев Г.С. Социальные связи человека в культуре // Культура, человек и картина мира.-М., 1987.

[2] Баткин Л.М. Европейский человек наедине с собой. Очерки о культурно-исторических основаниях и пределах личного самосознания.-М., 2000.

[3] Бауман 3. Индивидуализированное общество. - М., 2002.

[4] Гадамер Г. Истина и метод: Основы философской герменевтики.-М., 1988.

[5] Геллнер Э. Условия свободы. Гражданское общество и его исторические соперники. - М., 1995.

[6] Маркс К. Капитал.-Т.1. // Маркс К., Энгельс Ф. Соч.-М., 1960. - T. 23.

[7] Маркс K. Теории прибавочной стоимости // Маркс К., Энгельс Ф. Соч. - М., 1961.-Т. 26. - Ч. 3.

[8] Мамардашвили М. Форма превращенная // Философская энциклопедия. - М., 1971. - Т. 5.

[9] Менегетти А. Проект «Человек». - М., 2001. 